\title{
Substrate Ground State Binding Energy Concentration Is Realized as Transition State Stabilization in Physiological Enzyme Catalysis
}

\author{
Billy Mark Britt* \\ Department of Chemistry and Physics, Texas Woman's University, Denton, TX 76798, USA
}

Received 6 January 2004, Accepted 9 February 2004

\begin{abstract}
Previously published kinetic data on the interactions of seventeen different enzymes with their physiological substrates are re-examined in order to understand the connection between ground state binding energy and transition state stabilization of the enzyme-catalyzed reactions. When the substrate ground state binding energies are normalized by the substrate molar volumes, binding of the substrate to the enzyme active site may be thought of as an energy concentration interaction; that is, binding of the substrate ground state brings in a certain concentration of energy. When kinetic data of the enzyme/ substrate interactions are analyzed from this point of view, the following relationships are discovered: 1) smaller substrates possess more binding energy concentrations than do larger substrates with the effect dropping off exponentially, 2) larger enzymes (relative to substrate size) bind both the ground and transition states more tightly than smaller enzymes, and 3) high substrate ground state binding energy concentration is associated with greater reaction transition state stabilization. It is proposed that these observations are inconsistent with the conventional (Haldane) view of enzyme catalysis and are better reconciled with the shifting specificity model for enzyme catalysis.
\end{abstract}

Keywords: Enzyme catalysis, Ground state binding energy, Shifting specificity model, Transition state stabilization

\section{Introduction}

The purpose of this paper is to demonstrate that the binding of a substrate ground state to an enzyme active site may be thought of as the introduction of a concentration of energy to

*To whom correspondence should be addressed.

Tel: 940-898-2566; Fax: 940-898-2548

E-mail: mbritt@twu.edu the enzyme. Substrate ground state binding energies to enzyme active sites are calculated using $\Delta G_{b}=-\mathrm{RT} \ln \left(K_{m}\right)$ where $\Delta G_{b}$ is the binding free energy gained by the association of an enzyme with the substrate ground state and $K_{m}$ is the Michaelis constant. The free energy reduction observed upon binding reflects the sum of all noncovalent interactions between the substrate and active site, which are more favorable than the interaction between each and the solvent.

However, this analysis fails to consider that larger substrates have an intrinsically higher binding potential than smaller substrates since they possess more atoms, which might also be involved in these interactions. It is possible that a more favorable $\Delta G_{b}$ results from a larger substrate interacting poorly with an enzyme than a smaller substrate, which ostensibly interacts better on an atom-for-atom basis.

A simple way to estimate the potential with respect to the binding of a substrate on an atom by atom basis is to normalize the binding energy versus some aspect of the substrate molecular structure. A good measure of how much a substrate puts into binding can be obtained from $P_{G S}=$ $\mathrm{RT} \ln K_{n} / \mathrm{V}_{\mathrm{M}(\mathrm{s})}$ where $\mathrm{V}_{\mathrm{M}(\mathrm{s})}$ is the molar volume of the substrate calculated by summing all atomic volumes, as determined from van der waals radii, and $P_{G S}$ is the binding energy concentration of the interaction (unit analysis of $\mathrm{P}_{\mathrm{GS}}$ gives $\mathrm{J} / \mathrm{L}$ or $1000 \mathrm{~N} / \mathrm{m}^{2}$ ). The binding interaction may therefore be thought of from the substrate perspective as an introduction of an energy concentration or an applied interaction pressure.

As an application of this approach the binding affinities of hexokinase and urease for their physiological substrates were compared. Hexokinase exhibits an apparently much stronger affinity for glucose $\left(\Delta G_{b}=-29.1 \mathrm{~kJ} / \mathrm{mole}\right)$ than urease does for urea $\left(\Delta G_{b}=-11.3 \mathrm{~kJ} / \mathrm{mole}\right)$ (Barman, 1969). However, when these binding energies are normalized with respect to substrate molar volumes it is found that urea has the higher concentration of binding energy with $P_{G S}=197 \mathrm{~kJ} / \mathrm{L}$ for the urea/urease interaction versus $P_{G S}=162 \mathrm{~kJ} / \mathrm{L}$ for the hexokinase/glucose interaction.

Likewise, the binding energy concentration between an enzyme and a reaction transition state may be calculated using 
Table 1. Enzyme/substrate physical data

\begin{tabular}{|c|c|c|c|c|c|c|}
\hline Enzyme & $\begin{array}{l}\text { Enzyme empirical } \\
\text { formula }\end{array}$ & $\mathrm{V}_{\mathrm{E}(\mathrm{M})}(\mathrm{L})$ & Substrate & $\mathrm{V}_{\mathrm{S}(\mathrm{M})}(\mathrm{L})$ & $\mathrm{P}_{\mathrm{GS}}(\mathrm{kJ} / \mathrm{L})$ & $\mathrm{P}_{\mathrm{TS}}(\mathrm{kJ} / \mathrm{L})$ \\
\hline lysozyme (LYS) & $\mathrm{C}_{630} \mathrm{H}_{961} \mathrm{~N}_{177} \mathrm{O}_{190} \mathrm{~S}_{13}$ & 15.5 & $(\mathrm{NAG})_{2}$ & 0.436 & 49.1 & 105 \\
\hline acetylcholinesterase $(\mathrm{ACE})^{\mathrm{b}}$ & $\mathrm{C}_{3269} \mathrm{H}_{4954} \mathrm{~N}_{850} \mathrm{O}_{978} \mathrm{~S}_{30}$ & 79.1 & acetylcholine & 0.132 & 175 & 569 \\
\hline urease $(\mathrm{URE})^{\mathrm{c}}$ & $\mathrm{C}_{4000} \mathrm{H}_{6404} \mathrm{~N}_{1112} \mathrm{O}_{1120} \mathrm{~S}_{36}$ & 99.2 & urea & 0.0574 & 197 & 1390 \\
\hline glucoamylase $(\mathrm{GCA})^{\mathrm{d}}$ & $\mathrm{C}_{3013} \mathrm{H}_{4570} \mathrm{~N}_{782} \mathrm{O}_{1009} \mathrm{~S}_{13}$ & 73.7 & maltose & 0.342 & 55.6 & 193 \\
\hline isocitrate dehydrogenase (ICD) ${ }^{e}$ & $\mathrm{C}_{2145} \mathrm{H}_{3435} \mathrm{~N}_{575} \mathrm{O}_{627} \mathrm{~S}_{17}$ & 52.7 & isocitrate & 0.199 & 115 & 271 \\
\hline cytidine deaminase $(\mathrm{CD})^{f}$ & $\mathrm{C}_{1406} \mathrm{H}_{2196} \mathrm{~N}_{382} \mathrm{O}_{421} \mathrm{~S}_{11}$ & 34.4 & cytidine & 0.240 & 89.0 & 274 \\
\hline adenosine deaminase $(\mathrm{ADA})^{\mathrm{g}}$ & $\mathrm{C}_{1823} \mathrm{H}_{2834} \mathrm{~N}_{484} \mathrm{O}_{552} \mathrm{~S}_{14}$ & 44.5 & adenosine & 0.263 & 97.8 & 266 \\
\hline triosephosphate isomerase $(\mathrm{TPI})^{\mathrm{h}}$ & $\mathrm{C}_{1163} \mathrm{H}_{1877} \mathrm{~N}_{327} \mathrm{O}_{351} \mathrm{~S}_{6}$ & 28.8 & G3P & 0.127 & 153 & 402 \\
\hline carbonic anhydrase $(\mathrm{CA})^{i}$ & $\mathrm{C}_{1285} \mathrm{H}_{1961} \mathrm{~N}_{353} \mathrm{O}_{393} \mathrm{~S}_{3}$ & 31.3 & bicarbonate & 0.0433 & 266 & 993 \\
\hline creatine kinase $(\mathrm{CK})^{\mathrm{j}}$ & $\mathrm{C}_{1882} \mathrm{H}_{2941} \mathrm{~N}_{527} \mathrm{O}_{573} \mathrm{~S}_{17}$ & 46.4 & creatine, ATP & 0.477 & 21.4 & 103 \\
\hline fumarase $(F)^{k}$ & $\mathrm{C}_{2209} \mathrm{H}_{3540} \mathrm{~N}_{616} \mathrm{O}_{665} \mathrm{~S}_{20}$ & 54.7 & malate & 0.111 & 278 & 800. \\
\hline Gln-F6P-aminotransferase (GFA) & $\mathrm{C}_{2953} \mathrm{H}_{4737} \mathrm{~N}_{831} \mathrm{O}_{896} \mathrm{~S}_{17}$ & 73.2 & glutamine & 0.151 & 121 & 557 \\
\hline alcohol dehydrogenase $(A L D)^{\mathrm{m}}$ & $\mathrm{C}_{1636} \mathrm{H}_{2574} \mathrm{~N}_{442} \mathrm{O}_{488} \mathrm{~S}_{14}$ & 40.1 & ethanol & 0.0597 & 177 & 987 \\
\hline arginine decarboxylase $(\mathrm{ARD})^{\mathrm{n}}$ & $\mathrm{C}_{3758} \mathrm{H}_{5734} \mathrm{~N}_{1010} \mathrm{O}_{1134} \mathrm{~S}_{38}$ & 91.6 & arginine & 0.191 & 93.4 & 593 \\
\hline hexokinase $(\mathrm{HK})^{\circ}$ & $\mathrm{C}_{4522} \mathrm{H}_{7274} \mathrm{~N}_{1272} \mathrm{O}_{1369} \mathrm{~S}_{53}$ & 113 & glucose & 0.180 & 162 & 345 \\
\hline ketosteroid isomerase $(\mathrm{KI})^{p}$ & $\mathrm{C}_{1178} \mathrm{H}_{1931} \mathrm{~N}_{335} \mathrm{O}_{358} \mathrm{~S}_{13}$ & 29.5 & 5-androstene-3,17-dione & 0.366 & 57.1 & 180 \\
\hline orotidine-5-monophosphate & $\mathrm{C}_{1296} \mathrm{H}_{2078} \mathrm{~N}_{356} \mathrm{O}_{392} \mathrm{~S}_{10}$ & 32.1 & orotidine-5-monophosphate & 0.284 & 124 & 346 \\
\hline
\end{tabular}

$K_{m}$ valules (M) from Barman except where noted (1969)

${ }^{a}$ TSSE (transition state stabilization energy) from Chipman, 1971; $K_{m}$ is actual $K_{s}$ from Barman (1969); enzyme from dog milk

'TSSE from Harel et al. (1996); enzyme from cotton aphid;

'TSSE from Creighton; enzyme from jack bean

${ }^{\mathrm{D}} \mathrm{TSSE}$ and $K_{m}$ from Olsen et al. (1992); enzyme from human

'TSSE from Hurley and Remington, (1992); all other data from bakers yeast

'TSSE from Frick, 1987; enzyme from $E$. coli

${ }^{8}$ TSSE from Frick et al. (1987); $K_{m}$ from Fabianowski-Wajewska and Greger (1992); enzyme from rat

hTSSE from Hall and Knowles (1975); enzyme from chicken

'TSSE from Pocker and Meany (1967); enzyme from human

'TSSE from Creighton;enzyme from rabbit

kTSSE from Bearne and Wolfenden (1995); enzyme from pig

'TSSE from Tempczyk et al. (1992); enzyme from $E$. coli

${ }^{\mathrm{m}}$ TSSE from Creighton; enzyme from yeast

"TSSE from Wolfenden (2000); enzyme from E. coli

'TSSE from Koshland (1956); enzyme from cow

${ }^{p}$ TSSE and $K_{m}$ from Radzicka and Wolfenden (1995); enzyme from Pseudomonas testosteroni

'TSSE and $K_{m}$ from Radzicka and Wolfenden (1995); enzyme from bakers yeast

$\mathrm{P}_{\mathrm{TS}}=\mathrm{RT} \ln \left(k_{\text {cal }} / k_{\text {uncat }}\right) / \mathrm{V}_{\mathrm{M}(\mathrm{S})}$ where $k_{\text {cat }}$ and $k_{\text {uncal }}$ are the rate constants for the conversion of substrate to product for the catalyzed and uncatalyzed reactions, respectively.

When the interactions of reaction ground states and transition states with enzymes for physiologically relevant reactions are considered in this manner several interesting features emerge. First, it is found that $P_{G S}$ drops off exponentially with substrate volume, demonstrating that smaller substrates interact more strongly with enzymes on an atom-for-atom basis. Second, it is observed that the larger an enzyme is relative to its substrate the greater are the interactions of the reaction ground and transition states with the enzyme. Third, it is found that a strong ground state interaction with the enzyme is directly comrelated with the stabilization of the reaction transition state.

Finally, it is argued that these results are inconsistent with the conventional (Haldane) view of enzyme catalysis and more consistent with a view that invokes the active participation of the entire enzyme molecule in the catalytic event and that recognizes that a strong ground state interaction with the enzyme favors catalysis (Britt, 1993; Britt, 2004). The ideas presented here expand on those presented earlier by the author on this topic (Britt, 1997).

\section{Materials and Methods}

We consider only interactions between enzymes and their physiological substrates since this has driven the evolution of each enzyme's structure and function. Presented are previously published data from 17 such systems (Table 1). Enzyme empirical formulas were obtained using the ProtParam tool at the ExPASy Molecular 


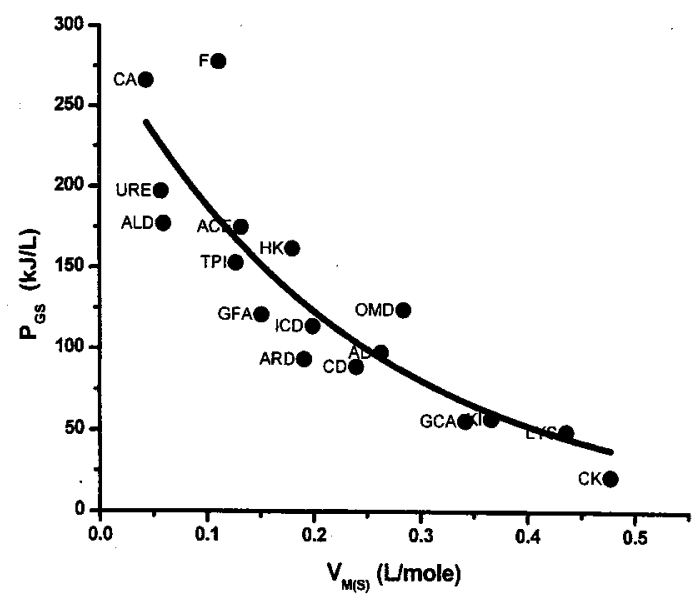

Fig. 1. Plot of $P_{G S}$ vs subtrate molar volume $V_{M(S)}$. The data trend is described as $P_{G S}=288 \mathrm{e}^{-4 \mathrm{~V}}$ where $\mathrm{V}$ is the substrate molar volume $\left(R^{2}=0.77\right)$.

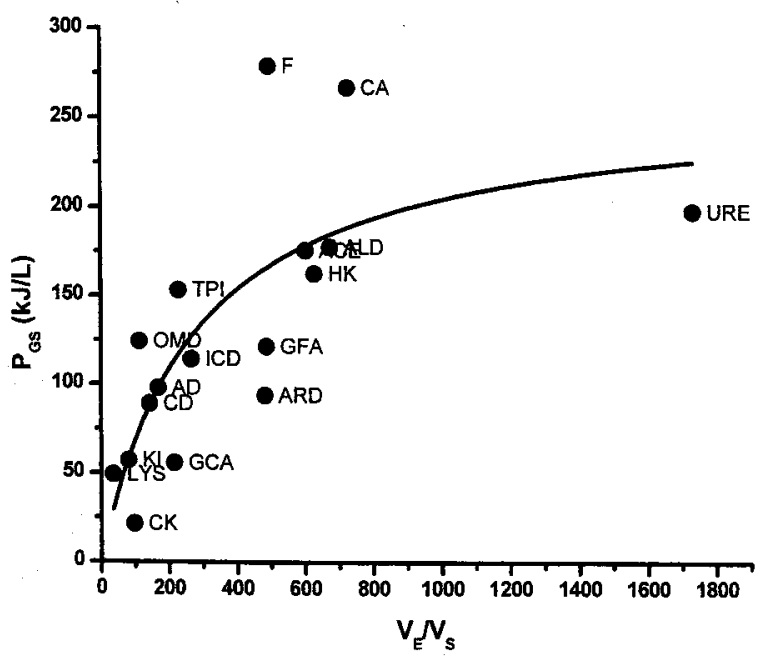

Fig. 2. Plot of $P_{G S}$ vs. $V_{E} / V_{s}$. The data trend is described by $P_{G S}$ $=261\left(\mathrm{~V}_{\mathrm{E}} / \mathrm{V}_{\mathrm{S}}\right) /\left[281+\left(\mathrm{V}_{\mathrm{E}} / \mathrm{V}_{\mathrm{S}}\right)\right]\left(\mathrm{R}^{2}=0.57\right)$.

Biology Server website. Enzyme and substrate volumes were calculated using the following van der Waals radii in pm: $\mathrm{C}(170)$, $\mathrm{H}$ (120), N (155), O (152), S (180), P (180). Volumes presented are the sums of the elemental van der Waals volumes for each enzyme or substrate. The trends presented in Figs. 1-4 were obtained using the curve fitting software provided in Microcal Origin.

\section{Results}

Figure 1 shows how the substrate ground state binding concentration or the applied interaction pressure $P_{G S}$ falls exponentially upon increasing substrate volume. Constraining the fit of the exponential to go to zero binding energy concentration for infinite volume yields a trend of $P_{G S}=288 e^{-4 V}$ where $\mathrm{V}$ in this equation is the substrate molar volume. These data illustrate that smaller substrates bring more binding

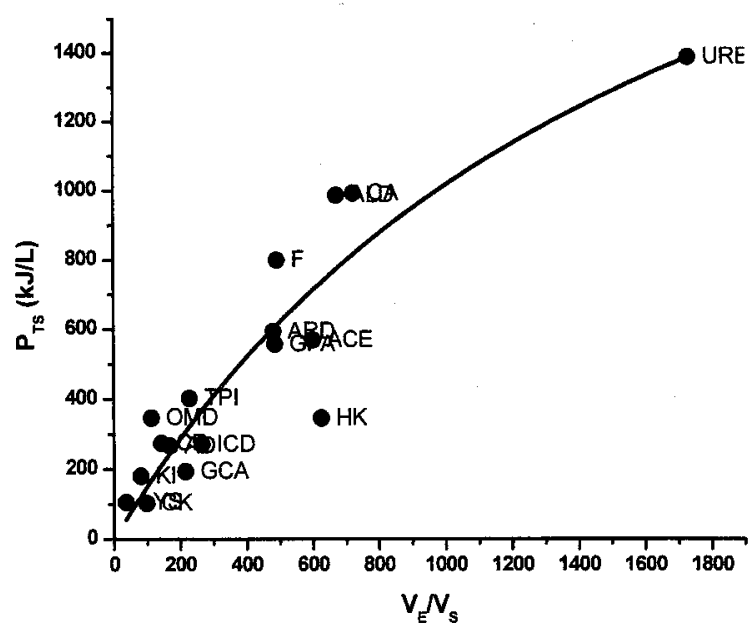

Fig. 3. Plot of $P_{T S}$ vs. $V_{E} / V_{S}$. The data trend is described by $P_{T S}$ $=2795\left(\mathrm{~V}_{\mathrm{E}} / \mathrm{V}_{\mathrm{S}}\right) /\left[1749+\left(\mathrm{V}_{\mathrm{E}} / \mathrm{V}_{\mathrm{S}}\right)\right]\left(\mathrm{R}^{2}=0.83\right)$.

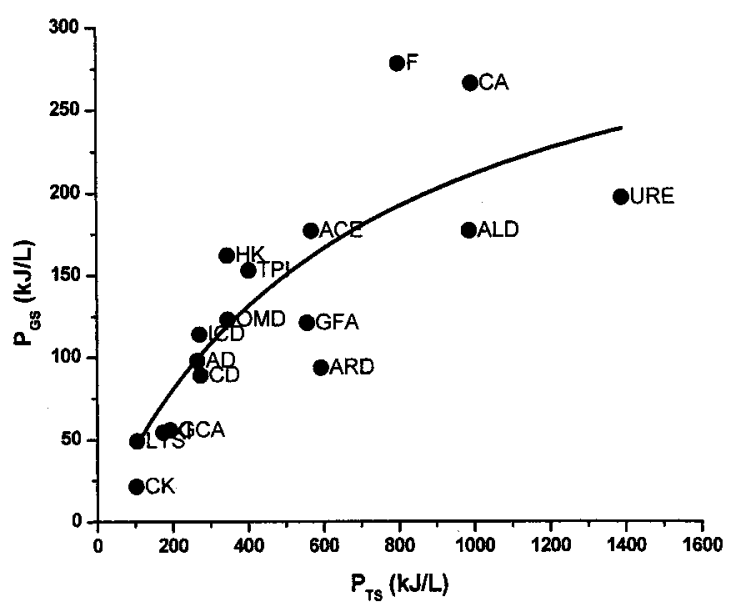

Fig. 4. Plot of $P_{G S}$ vs. $P_{T S}$. The data are described by $P_{G S}=$ $357 \mathrm{P}_{\mathrm{TS}} /\left(691+\mathrm{P}_{\mathrm{TS}}\right)\left(\mathrm{R}^{2}=0.71\right)$.

energy concentrations to the enzyme than larger substrates. The trend in Fig. 1 suggests that the maximal affinity a substrate can bring to the active site is approximately $300 \mathrm{~kJ} /$ mole or $3 \times 10^{5} \mathrm{~N} / \mathrm{m}^{2}$ or $3 \mathrm{~atm}$.

It is interesting to consider the effect on ground state binding of the relative size of an enzyme to its substrate. Figure 2 shows how substrate ground state binding energy concentration increases hyperbolically with increasing $V_{E} / V_{S}$. The most straightforward explanation for the observed trend is that larger enzymes are better able to tweak active site groups for optimal interaction with substrates than are smaller enzymes.

As the interaction of the reaction ground state with the enzyme may be considered a binding energy concentration effect, so can the interaction of the transition state. Again, we ask what relationship exists between the relative size of an enzyme and its ability to interact with and thus stabilize the transition state. Figure 3 shows how $\mathrm{P}_{\mathrm{TS}}$ increases hyperbolically 
with $\mathrm{V}_{\mathrm{E}} / \mathrm{V}_{\mathrm{S}}$. It appears that larger enzymes (relative to their substrates) are better able to bind the reaction transition state. Again, the most straightforward explanation for this effect is that the increased enzyme mass allows for an optimization of contacts with the transition state. It is important to note that the conventional explanation of enzyme catalysis has no active role for the bulk of the enzyme not constituting the active site, and therefore, allows no predictions based on relative sizes and the abilities of enzymes to bind ground and transition states.

Finally, Fig. 4 shows how strong ground state binding is correlated with greater transition state stabilization.

\section{Discussion}

The data presented here are not easily interpreted in terms of the Haldane model for enzyme catalysis, which allocates no active role for the enzyme mass not constituting the active site, and which maintains that poor ground state binding is associated with enhanced transition state stabilization (Fersht, 2000). Instead, the data support an alternate view of enzyme catalysis (Britt, 1993; Britt, 1997; Britt, 2004), which requires the participation of the entire enzyme molecule in the catalytic event, and which maintains that strong ground state interactions favor catalysis. This view advocates that the physiological enzyme exists in a relatively high energy conformation and has an active site geometry that favors interaction with the reaction ground state over the transition state. Interaction of the ground state with the enzyme via the same noncovalent interactions that govern protein tertiary structure necessarily induces a global conformational change, which transforms the active site from a ground state complementarity to a transition state complementarity, and in the process transforms the substrate from the ground state to the transition state. The reaction is facilitated by the transient adoption of a more stable enzyme global conformation in the transition state; that is, though the total energy of the system must be, by definition, at a maximum, the enzyme-localized energy achieves an energy minimum at this point. The substrate ground state binding energy is thus used to trigger this conformational change. The greater the interaction of the ground state with the enzyme the more efficient the enzyme conformational relaxation and the more efficient is the catalysis. This model therefore correlates strong substrate ground state interactions with the enzyme with enhanced catalysis.

This model also suggests an explanation for the correlation between catalytic efficiency and increased enzyme mass. First, a larger enzyme mass increases the probability that the enzyme possesses two catalytically relevant conformations because there is greater potential for the tweaking of active site functionalities. Secondly, the mechanism for stabilization of one folded protein form relative to another involves the optimization of nonpolar side chain contacts. Obviously, a larger enzyme possesses an intrinsically greater potential for energy minimization.

Acknowledgments The author thanks J. B. Chaires and W. D. Edwards for helpful discussion. This work was supported by the TWU Research Enhancement Program and the Robert A. Welch Foundation.

\section{References}

Barman, T. E. (1969) Enzyme Handbook, Springer-Verlag, New York, USA.

Bearne, S. L. and Wolfenden, R. (1995) Enzymic hydration of an olefin: the burden borne by fumarase. J. Am. Chem. Soc. 117, 9588-9589.

Britt, B. M. (1993) A shifting specificity model for enzyme catalysis. J. Theor. Biol. 164, 181-190.

Britt, B. M. (1997) For enzymes, bigger is better. Biophys. Chem. 69, 63-70.

Britt, B. M. (2004) Understanding enzyme structure and function in terms of the shifting specificity model. J. Biochem. Mol. Biol., 37, 394-401.

Creighton, T. E. (1983) Proteins in Catalysis, p. 420, W. H. Freeman and Co., New York, USA.

Chipman, D. M. (1971) A kinetic analysis of the reaction of lysozyme with oligosaccharides from bacterial cell walls. Biochemistry 10, 1714-1722.

Fabianowski-Wajewska, K. and Greger, J. (1992) Adenosine deaminase: physical and chemical properties of partially purified mitochondrial and cytosol enzyme from rat liver. Acta Biochimica Polonica 39, 193-204.

Fersht, A. (2000) Structure and mechanism in protein science; in Enzyme-substrate complementarity and the use of binding energy in catalysis, pp. 349-375, W. H. Freeman and Co., New York, USA

Frick, L., MacNeela, J. P. and Wolfenden, R. (1987) Transition state stabilization by deaminases: rates of nonenzymatic hydrolysis of adenosine and cytidine. Bioorg. Chem. 15, 100108.

Hall, A. and Knowles, J. (1975) Uncatalyzed rates of enolization of dihydroxyacetone phosphate and of glyceraldehyde 3phosphate in neutral aqueous solution. Quantitative assessment of the effectiveness of an enzyme catalyst. Biochemistry 14, 4348-4352.

Harel, M., Quinn, D. M., Nair, I., Silman, I. and Sussman, J. L. (1996) The x-ray structure of a transition state analog complex reveals the molecular origins of the catalytic power and substrate specificity of acetylcholinesterase. J. Am. Chem. Soc. 118, 2340-2346.

Hurley, J. H. and Remington, S. J. (1992) Contribution of charged side chains, $\mathrm{Mg}^{2+}$, and solvent exclusion to enzymic $\beta$ decarboxylation of $\alpha$-keto acids. J. Am. Chem. Soc. 114, 47694773.

Koshland, D. E., Jr. (1962) The comparison of non-enzymic and enzymic reaction velocities. J. Theor. Biol. 2, 75-86.

Olsen, K., Svensson, B. and Cristensen, U. (1992) Stopped-flow fluorescence and steady-state kinetic studies of ligand- binding reactions of glucoamylase from Aspergillus niger. Eur. $J$. 
Biochem. 209, 777-784.

Pocker, Y. and Meany, J. E. (1967) A comparative study of enzymatic and metal ion catalyzed hydration of pyridine aldehydes. J. Am. Chem. Soc. 89, 631-636.

Radzicka, A. and Wolfenden, R. (1995) A proficient enzyme. Science 267, 90-93.

Snider, M. J. and Wolfenden, R. (2000) The rate of spontaneous decarboxylation of amino acids. J. Am. Chem. Soc. 122, 11507-11508.

Tempczyk, A., Tarnowska, M., Liwo, A., and Borowski, E. (1992) A theoretical study of glucosamine synthase. II. combined quantum and molecular mechanics simulation of sulfhydryl attack on the carboxyamide group. Eur. Biophys. J. 21, 137 145. 